\title{
Epidemiological Profile of Hepatitis B Virus Infection in Iran in the Past 25 years; A Systematic Review and Meta-analysis of General Population Studies
}

Zahra Mohammadi ${ }^{1}$, Abbasali Keshtkar ${ }^{2}$, Sareh Eghtesad ${ }^{1}$, Alireza Jeddian ${ }^{1}$, Ali Akbar Pourfatholah ${ }^{3,4}$, Mahtab Maghsudlu ${ }^{3}$, Maryam Zadsar ${ }^{3}, Z^{2}$ ahra Mahmoudi ${ }^{1}$, Amaneh Shayanrad $^{1}$, Hossein Poustchi $^{1 *}$, Reza Malekzadeh ${ }^{5}$

1. Liver and Pancreatobiliary Diseases Research Center, Digestive Diseases Research Institute, Tehran University of Medical Sciences, Tehran, Iran

2. Department of Health Sciences Education Development, School of Public Health, Tehran University of Medical Sciences, Tehran, Iran

3. Blood Transfusion Research Center, High Institute for Research and Education in Transfusion Medicine, Tehran, Iran

4. Department of Immunology, Faculty of Medical Science, Tarbiat Modares University, Tehran, Iran

5. Digestive Diseases Research Center, Digestive Diseases Research Institute, Tehran University of Medical Sciences, Tehran, Iran

\footnotetext{
* Corresponding Author:

Hossein Poustchi, MD

Digestive Diseases Research Institute, N. Kargar Ave, Shariati Hospital, Tehran, Iran Tel: + 982182415204 Fax: +98 2182415400 Email: h.poustchi@gmail.com Received: 12 Jun. 2015 Accepted: 18 Oct. 2015
}

\section{ABSTRACT}

\section{BACKGROUND}

Chronic hepatitis B virus (HBV) infection is one of the most important health problems worldwide with a high rate of morbidity and mortality. It is a major risk factor for cirrhosis and liver cancer. Currently, Iran is located in the intermediate HBV zone; however, recent studies have provided some evidence indicating an epidemiological change in the country. The aim of this study was to estimate the prevalence of HBV in Iran.

\section{METHODS}

A systematic review was conducted to evaluate the studies performed in the past 25 years that have reported the prevalence of HBV infection and its associated factors in the Iranian general population (1990-2014). Any study assessing and reporting serum $\mathrm{Hbs} \mathrm{Ag}$ levels was included in this review.

\section{RESULTS}

After excluding all impertinent studies, 19 eligible studies were included in the analysis. The overall prevalence of HBV was $3 \%$ (95\% CI $2 \%$ to $3 \%)$. Its distribution showed that the prevalence of HBV varies in different provinces from $0.87 \%$ to $8.86 \%$. The HBV rate was highest in the Golestan $(8.86 \%)$ and lowest in the Kurdistan $(0.87 \%)$ provinces.

\section{CONCLUSION}

This study provides some evidence about the prevalence of HBV in Iran. However, the collected data was very heterogenic, even within a single province, which made it hard to estimate a single-point prevalence. High quality studies are needed to find reliable information about HBV prevalence and to decrease the heterogeneity of results in the country.

\section{KEYWORDS}

Hepatitis B; Iran; General population; Epidemiology; Systematic review

\section{Please cite this paper as:}

Mohammadi Z, Keshtkar AA, Eghtesad S, Pourfatholah AA, Maghsudlu M, Zadsar M, Mahmoudi Z, Shayanrad A, Poustchi H, Malekzadeh R. Epidemiological Profile of Hepatitis B Virus Infection in IRAN in the Past 25 years; A Systematic Review and Meta-analysis of General Population Studies. Middle East J Dig Dis 2015;8:5-18. DOI: 10.15171/ mejdd.2016.01

\section{INTRODUCTION}

Hepatitis B virus (HBV) remains an important cause of acute and chronic liver disease worldwide. ${ }^{1,2}$ Based on the World Health Organization (WHO) reports, more than 2 billion people in the world are affected by HBV and nearly 350 million individuals have suffered 
from its consequences, such as liver cirrhosis and hepatocellular carcinoma. ${ }^{3}$ The prevalence of HBV carriers varies in different regions with the lowest rates in North America, northern and western Europe, and Australia and the highest prevalence in southeast Asia, China, sub-Saharan Africa, and the Amazon Basin. ${ }^{4-5}$

$\mathrm{HBV}$ is also prevalent in Iran. Based on the Survey of Health and Disease in the Islamic Republic of Iran in 1990, the sero-prevalence of HBV in the Iranian population was $1.7 \%(0-3.9 \%) .{ }^{6}$ However, other studies conducted in Iran in this regard, have provided some data showing higher HBV prevalences, varying from 2.7 to $9.7 \%,{ }^{6-8}$ Vaccination of neonates against HBV infection started in 1993 as a part of a nationwide public health promotion program, with a $99 \%$ coverage. As a result, a change in the epidemiology of this disease is expected to be seen, especially in the vaccinated generation. ${ }^{9-10}$ Currently, an increase in disease prevalence is observed in older individuals who were not vaccinated at birth. ${ }^{10}$ And HBV's main mode of transmission is no longer vertical, but instead, it is transmitted mostly horizontally through contact with infected blood or body fluids. ${ }^{9}$ Other countries with neonatal vaccination programs, have also observed a similar change in the pattern of HBV transmission.

Based on the last systematic review conducted on the Iranian population in 2008 , the prevalence of $\mathrm{HBV}$ in men and women was reported at $2.55 \%$ and $2.03 \%$, respectively. ${ }^{11}$ However, some of the studies included in that report did not include subjects who met the definition of "general population", which is a very important principle in epidemiological studies. According to Shapiro and colleagues "general population" refers to all individuals without reference to any specific characteristic. It can refer to the entire human species, but smaller groups can be said to be the representative of the general population if they have the same male to female ratio, and persons from different age groups. These are the most important factors, among other qualifications. ${ }^{12}$

The studies conducted in Iran, have shown regional differences in HBV prevalence throughout the country. The most important issue however, is to estimate a single point value for the general population. Therefore, the first aim of this study was to systematically review all evidence on HBV infection in Iran and to make an overall estimate of HBV prevalence. The second aim was to identify trends in infection and national differences in HBV prevalence, as well as to assess possible sources of heterogeneity.

\section{MATERIALS AND METHODS}

\section{Eligibility criteria}

All population-based studies in the Iranian population including individuals of any age, sex, or ethnicity that had assessed HBV serology were included. Search was not limited by language or study design.

\section{Information sources and search}

Both electronic and hand searching were used in this study. The main keywords in this systematic review included: "Hepatitis B", "HBV", "General population", "prevalence", and "Iran". To assess the prevalence of HBV in the Iranian general population, not only were national and international databases searched, but also reference lists were also screened to find as many publications as possible. Electronic databases of biological and health sciences including MEDLINE (pub med), Scopus, EMBASE, Ebsco, Science Citation Index Expanded, Ovid, Google Scholar, Iran Medex, Magiran, and Scientific Information Database (SID) were searched. In each database, the appropriate search terms were applied.

In addition, through ULRICHS web, key journals for this issue were identified, which included the Scientific Journal of Iranian Blood Transfusion Organization (SJIBTO), Hepatitis Monthly, and Blood. The main concepts of these journals were hepatitis, infection, and blood. To find grey literature, abstract books from national and international congresses on hepatitis, infectious diseases, and blood, experts' curriculum vitae in this field, and national reports from the Iranian Ministry 
of Health and Medical Education and the Iranian Blood Transfusion Organization (IBTO) were also reviewed to further ensure that pertinent articles are not missed.

\section{Definition of study population and hepatitis B infection}

Studies performed in the general population, that included HBs Ag positive individuals-diagnosed through blood tests such as enzyme linked immuno-sorbent assay (ELISA) or polymerase chain reaction (PCR) were included in this systematic review. ${ }^{13-17}$

\section{Study selection and data collection process}

After carrying out the explained searches, publications of interest were selected based on titles and abstracts. The full texts of all selected publications were assessed for pertinence. If the full texts of the papers were not available, they were obtained through correspondence with the authors. This was followed by the extraction of the relevant data from the articles through the steps described in figure 1. The process initially performed by two reviewers. If there was heterogeneity in their opinion, a third reviewer reassessed the literature.

\section{Data extraction and quality assessment}

Data extraction forms consisted of the following data from each article: title, authors' names, type of report, and the electronic database where the article was archived, as well as subjects' demographic information such as mean age, age ranges, and sex, and details of the study methodology including the location and duration of the study, sampling methods, sample size, exclusion criteria, mode of hepatitis detection (serology and genetic), type/name of diagnostic kits used and the actual prevalence of HBV reported. The data of the forms were entered into SPSS software (version 18). Methodological qualities of the included studies were investigated using a modified STROBE checklist. Two reviewers evaluated each article's quality based on the checklist, and if a consensus was not reached, a third reviewer reassessed the manuscript.

\section{Data analyses}

All meta-analysis methods were performed using STATA version 11.1. The random effect model was used for combining the prevalence of HBV serology markers. The prevalence of HBV seromarkers in the total population as well as the agegroup and sex-specific prevalence were used as the main outcome measures. 95\% confidence intervals were calculated using the Binomial Exact Method. Heterogeneity was explored by subgroup analysis and meta-regression methods. ${ }^{12}$ statistic was used as the heterogeneity index and measurements greater than $50 \%$ indicated severe heterogeneity. Begg's test, Egger's test, and funnel plot were used for assessing publication bias. ${ }^{18-19}$ Given the fact that prevalence does not have a normal distribution, a prevalence index was first calculated using the logit/logit of prevalence and the standard error of logit prevalence, then a funnel plot was generated. ${ }^{20}$

\section{RESULTS}

\section{Study Selection}

National and international databases were used in this systematic review. The search strategies used in each databases were different. The studies found were screened for eligibility and included in the review if they met the inclusion criteria. The reasons by which articles were excluded are shown in figure 1.

\section{Study characteristics}

Nineteen pertinent studies were included in the systematic review with sample sizes ranging from 410 to 46,631 (table 1). A total of 133,958 individuals from the general population were examined through these studies. With the exception of four studies that did not distinguish sexes in their sample size, 18,366 male and 18,593 female participants were reported. The studies were from various provinces; three studies from Golestan (13.64\%), three from Sistan \& Balochestan (13.64\%), two studies from East Azarbaijan (9.09\%), two from Hamedan (9.09\%), and two from Khorasan Razavi (9.09\%). There was also one study from each of the following provinces: Tehran, Yazd, Qom, Kurdis- 


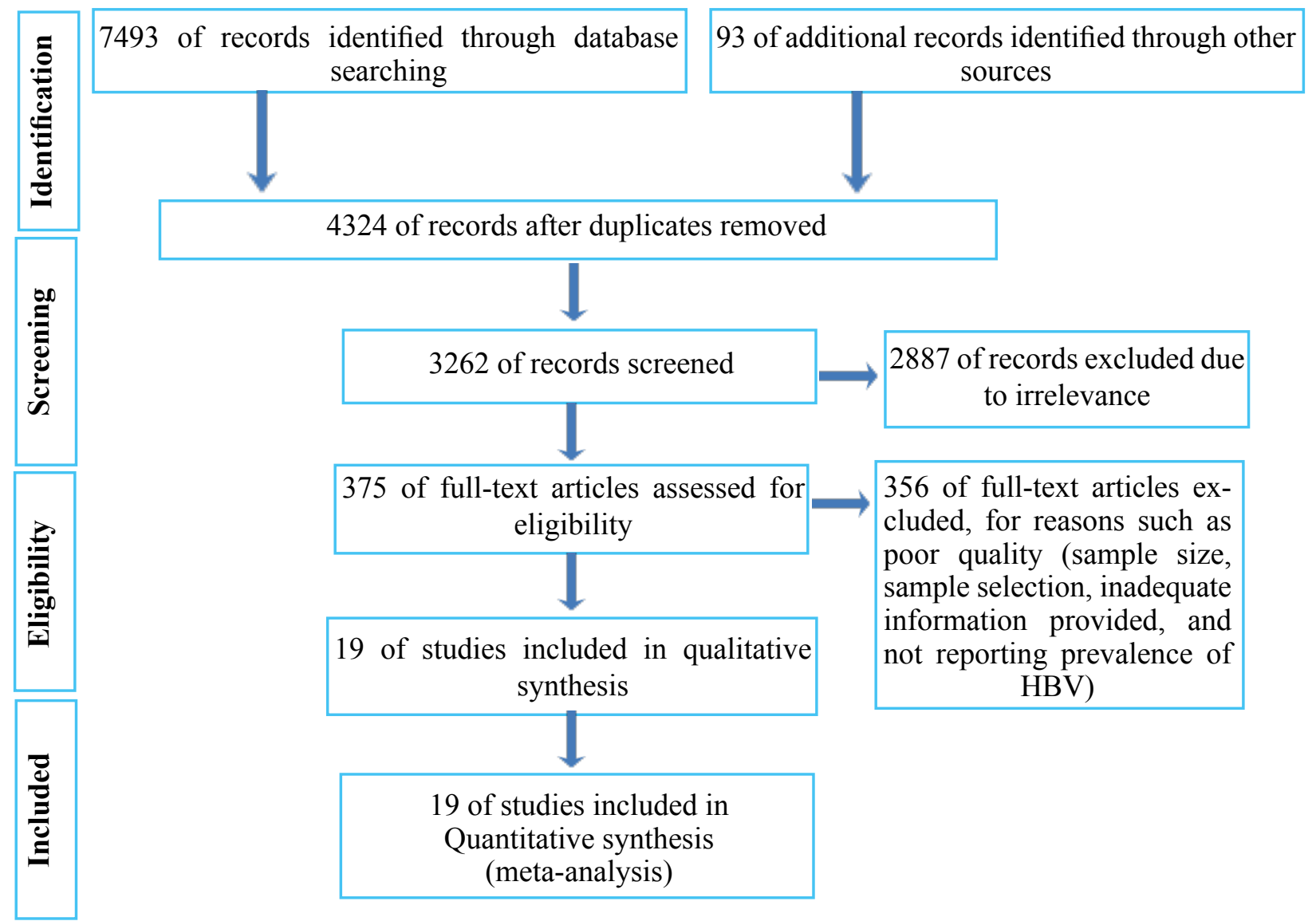

Fig. 1: Flow diagram of the literature search

tan, Lorestan, Isfahan, Hormozgan, and Khorasan (4.55\%). In addition, two national surveys were also included. Of these articles, 13 (61.9\%) were performed in both urban and rural areas while the remaining were in urban areas only. In all studies included in the systematic review, both sexes were examined. Finally, 95.24\% of studies used a cluster sampling method for sample selection.

All the studies used ELISA methods with Dade Behring, Hepa Nostike, and Diasorin being the most commonly used diagnostic kits. It is noteworthy to say that only the study from Khorasan Razavi used the genetic method (PCR) in addition to ELISA for the diagnosis of HBV. The PCR-based prevalence of HBV DNA in the population of that province was $3.1 \%$.

\section{Meta-analysis}

The HBV prevalence reported by the authors of the studies included in this review ranged from $0.87 \%$ to $8.86 \%$. As shown in figure 2 , the overall prevalence estimated by the meta-analysis was $3 \%$ (95\% CI $2 \%$ to $3 \%$ ). There was heterogeneity in HBV prevalence in different provinces $(\mathrm{dF}=$ $\left.20, \mathrm{I}^{\wedge} 2=95.2 \%, p<0.001\right)$. Sex was examined as a possible source of heterogeneity; however, it was not found to be the source, since the prevalence of hepatitis ranged from $2 \%$ to $3 \%$ in female and $2 \%$ to $4 \%$ in male participants $\left(\mathrm{df}=13, \mathrm{I}^{\wedge} 2=91.2 \%\right.$, $p<0.001$, female $),\left(\mathrm{df}=13, \mathrm{I}^{\wedge} 2=90.2 \%, p<0.001\right.$, male) (figures 3 and 4, respectively). Neither age, nor diagnostic kits were possible sources of heterogeneity.

The studies were placed into 3-year interval categories (figure 5). The highest prevalence was seen in the years 2004-2006 (figure 6). After these years, the trend declined. Based on subgroup analyses, the HBV distribution prior to 1997 was about 2-4\% (fig- 
Table 1: Characteristics of studies included in the HBV prevalence meta-analysis in the general Iranian population

\begin{tabular}{|c|c|c|c|c|c|c|c|c|}
\hline Code & First Author & Year & Province & $\begin{array}{c}\text { Sample } \\
\text { Size }\end{array}$ & $\begin{array}{c}\text { Age } \\
\text { Range }\end{array}$ & $\begin{array}{c}\text { Hbs Ag } \\
\text { Prevalence } \\
\text { (\%) "Total" }\end{array}$ & $\begin{array}{c}\text { Hbs Ag } \\
\text { Prevalence } \\
\text { (\%) "Male" }\end{array}$ & $\begin{array}{c}\text { HbsAg } \\
\text { Prevalence } \\
\text { (\%) "Female" }\end{array}$ \\
\hline 1 & Bayat ${ }^{21}$ & 2000 & $\begin{array}{c}\text { Azarbayjan } \\
\text { sharghi }\end{array}$ & 4207 & $* \mathrm{NR}$ & 1.2 & $* \mathrm{NR}$ & $* \mathrm{NR}$ \\
\hline 2 & Hasan Zade 22 & 1997 & $\begin{array}{c}\text { Azarbayjan } \\
\text { sharghi }\end{array}$ & 3409 & $2-69$ & 2.9 & 3.5 & 2.5 \\
\hline 3 & Abdolahi ${ }^{23}$ & 2004 & Golestan & 1850 & $25-65$ & 8.86 & 10.8 & 8.6 \\
\hline 4 & Merat ${ }^{7}$ & 2007 & Golestan & 1896 & $18-65$ & 5.1 & 5.4 & 4.8 \\
\hline 5 & Jamali ${ }^{24}$ & 2006 & Golestan & 2049 & $18-75$ & 5.0 & 5.4 & 4.7 \\
\hline 6 & Amini 25 & $* \mathrm{NR}$ & Hamedan & 4930 & $* \mathrm{NR}$ & 2.49 & $* \mathrm{NR}$ & $* \mathrm{NR}$ \\
\hline 7 & Alizade ${ }^{26}$ & 2001 & Hamedan & 1824 & $6-93$ & 2.3 & $* \mathrm{NR}$ & *NR \\
\hline 8 & Merat ${ }^{7}$ & 2007 & Hormozgan & 1455 & $18-65$ & 2.7 & 3.4 & 2.0 \\
\hline 9 & Nokhodiyan ${ }^{27}$ & 2005 & Isfahan & 816 & 6-Max & 1.3 & 1.8 & 7.0 \\
\hline 10 & Farhat ${ }^{28}$ & 1997 & Khorasan & 4528 & $2-100$ & 3.6 & $* \mathrm{NR}$ & $* \mathrm{NR}$ \\
\hline 11 & Shakeri ${ }^{29}$ & 2010 & $\begin{array}{c}\text { Khorasan } \\
\text { Razavi }\end{array}$ & 3198 & $15-65$ & 1.0 & 1.6 & 0.7 \\
\hline 12 & Fathi-Moghadam ${ }^{30}$ & 2009 & $\begin{array}{c}\text { Khorasan } \\
\text { Razavi }\end{array}$ & 1678 & $1-90$ & 1.39 & 2.0 & 0.89 \\
\hline 13 & Alavian ${ }^{31}$ & $* \mathrm{NR}$ & Kurdistan & 1613 & $6-65$ & 0.87 & 1.1 & 0.75 \\
\hline 14 & Ali Papi ${ }^{32}$ & 2013 & Lorestan & 454 & $* \mathrm{NR}$ & 5.9 & 6.2 & 5.7 \\
\hline 15 & Zali $^{6}$ & 1990 & $\begin{array}{c}\text { National } \\
\text { Survey }\end{array}$ & 39841 & $2-69$ & 1.7 & 1.9 & 1.5 \\
\hline 16 & Zali $^{9}$ & 1998 & $\begin{array}{c}\text { National } \\
\text { Survey }\end{array}$ & 46631 & $2-69$ & 1.7 & 1.9 & 1.5 \\
\hline 17 & Ghadir ${ }^{33}$ & $* \mathrm{NR}$ & Qom & 3690 & $* \mathrm{NR}$ & 1.3 & 1.6 & 1.1 \\
\hline 18 & $\begin{array}{l}\text { Ansari } \\
\text { moghadam }{ }^{34}\end{array}$ & 2009 & $\begin{array}{l}\text { Sistan Bal- } \\
\text { uchestan }\end{array}$ & 2587 & $10-88$ & 2.5 & 3.2 & 2.2 \\
\hline 19 & Salehi ${ }^{35}$ & *NR & $\begin{array}{l}\text { Sistan Bal- } \\
\text { uchestan }\end{array}$ & 3989 & $6-65$ & 3.38 & $* \mathrm{NR}$ & *NR \\
\hline 20 & Salehi ${ }^{36}$ & 1997 & $\begin{array}{l}\text { Sistan Bal- } \\
\text { uchestan }\end{array}$ & 410 & Min-60 & $* * \mathrm{NE}$ & $* \mathrm{NR}$ & *NR \\
\hline 21 & Merat $^{7}$ & 2007 & Tehran & 2327 & $18-65$ & 2.3 & 2.7 & 1.8 \\
\hline 22 & Sharifi ${ }^{37}$ & 1998 & Yazd & 576 & *NR & 6.42 & $* \mathrm{NR}$ & $* \mathrm{NR}$ \\
\hline
\end{tabular}

"NR: No Reported

"NE: No Evaluated

ure 7). HBV prevalence ranged from 1-3\%, 1-9\%, $2-4 \%$, and $1-3 \%$ in $1998-2000,2004-2006,2007-$ 2009, and 2010-2013 respectively (figures 8-11). There was heterogeneity in all groups $(p<0.001)$.

The funnel plot analysis performed for this systematic review showed the distribution to be symmetrical, without any significant publication bias (figure 12). Egger's test and Begg's test also confirmed these results. According to Begg's test the value for $\mathrm{Z}$ equaled $0.88(p=0.38)$ and based on $\mathrm{Eg}$ ger's test the bias score equaled $3.09(p=0.22)$, both showing that there is no publication bias.

\section{DISCUSSION}

HBV is a serious global public health problem. ${ }^{2}$ Based on the presented articles, the prevalence of HBV showed an increasing trend up to 2004, peaked during 2004-2006, and decreased thereafter. Other countries in the Middle East region, such as Turkey and Saudi Arabia, also showed a similar peak in HBV prevalence in 2004..$^{38-40}$

In Iran, a decline in HBV was seen after 2006, 


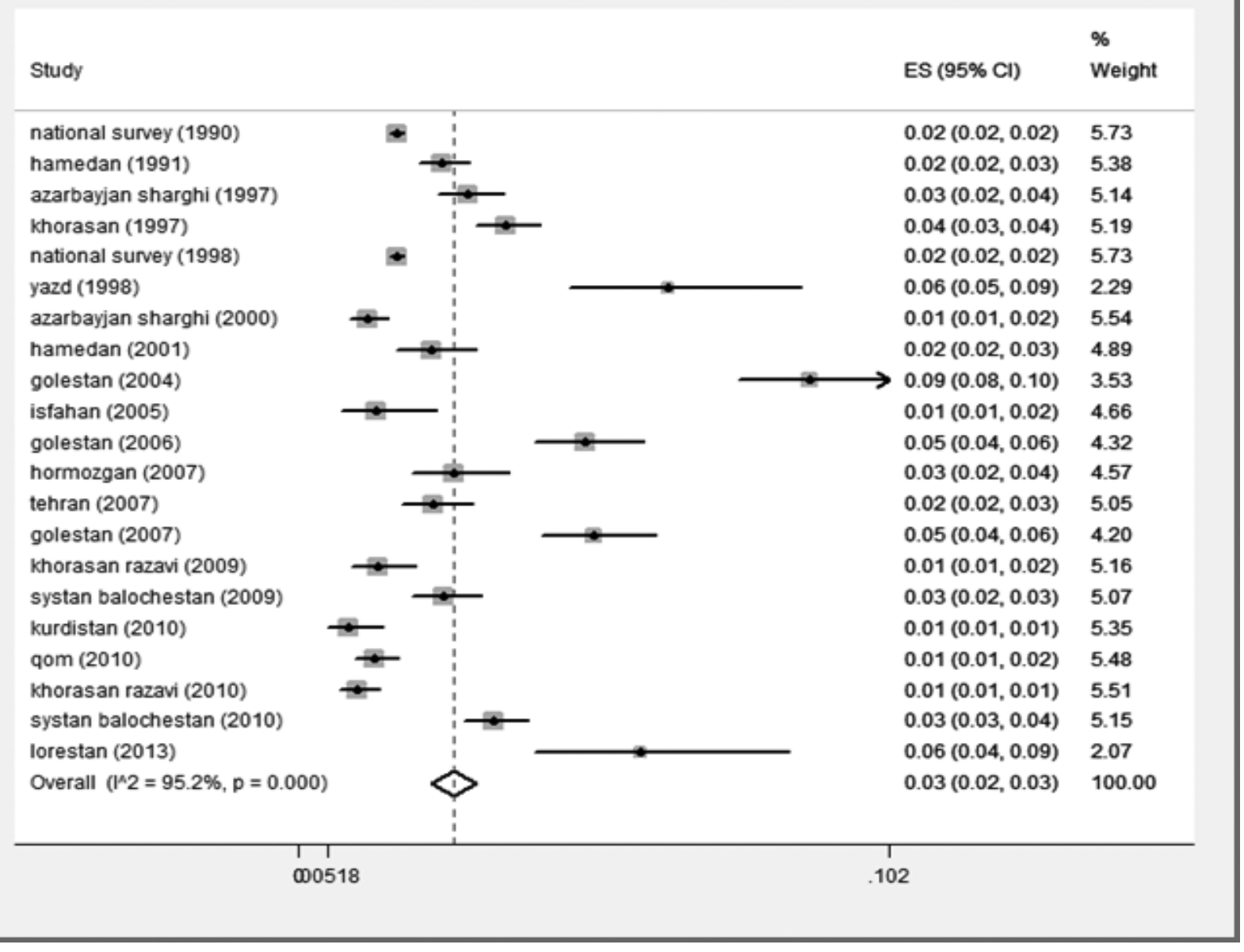

Fig. 2: Forest plot of the studies on HBV prevalence in Iran-both sexes were included

which may be related to the implementation of the $1993 \mathrm{HBV}$ vaccination program. Similarly, in Turkey and Saudi Arabia, who also initiated national immunization programs for $\mathrm{HBV}$ in 1998 and 1989, respectively, there was a decline in HBV prevalence after $2006 .^{38-40}$ In addition, in the past few years, all pregnant women in Iran are required by law to be checked for HBV and in case a mother is found to be an HBV carrier, adequate instructions are given to inject her newborn with hepatitis B immunoglobulin (HBIG) immediately after birth. This campaign may have also affected the decreased HBV rates. Also, another immunization program in youth has taken place in the past decade, checking the immunization status of 18-year-old, and vaccinating them if needed. Finally, the decline in HBV observed in Iran could also be attributed to in- creased awareness about HBV transmission, since a lack of knowledge in this regard has been shown to be associated with higher disease rates. ${ }^{2}$ In Iran, several national campaigns through the social media networks have tried to raise public awareness about HBV and its routes of transmission. Increasing the knowledge of healthcare providers has also decreased HBV transmission and prevalence. ${ }^{41-42}$

HBV distribution across the world shows variations depending on geographical location. ${ }^{43}$ Based on the data extracted from the literature reviewed for this study, the rates of HBV prevalence are heterogenic both among different provinces (from $0.87 \%$ to $8.86 \%$ ), and even within a single province. This heterogeneity within a single province is due to the fact that the studies were conducted at different time points. For example, in Goles- 


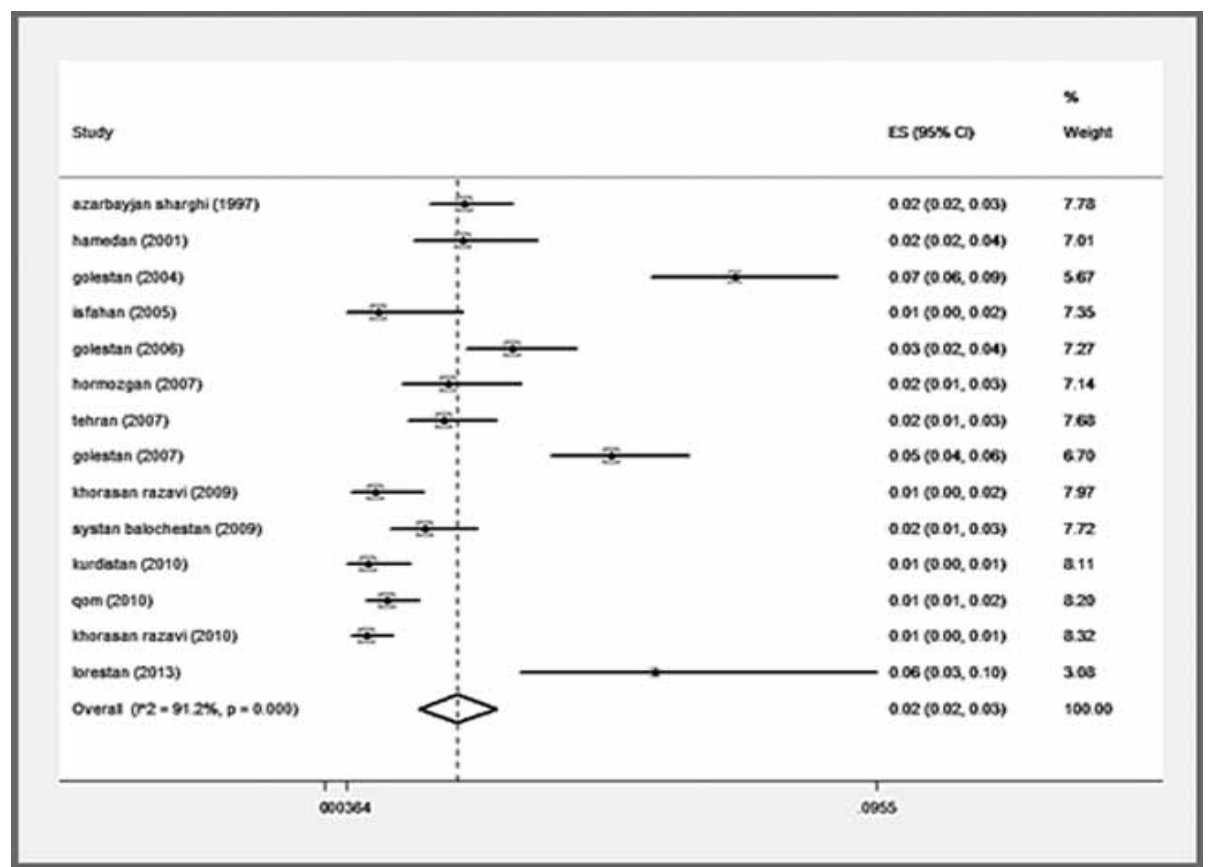

Fig. 3: Forest plot of the studies on HBV prevalence in Iran-female participants only

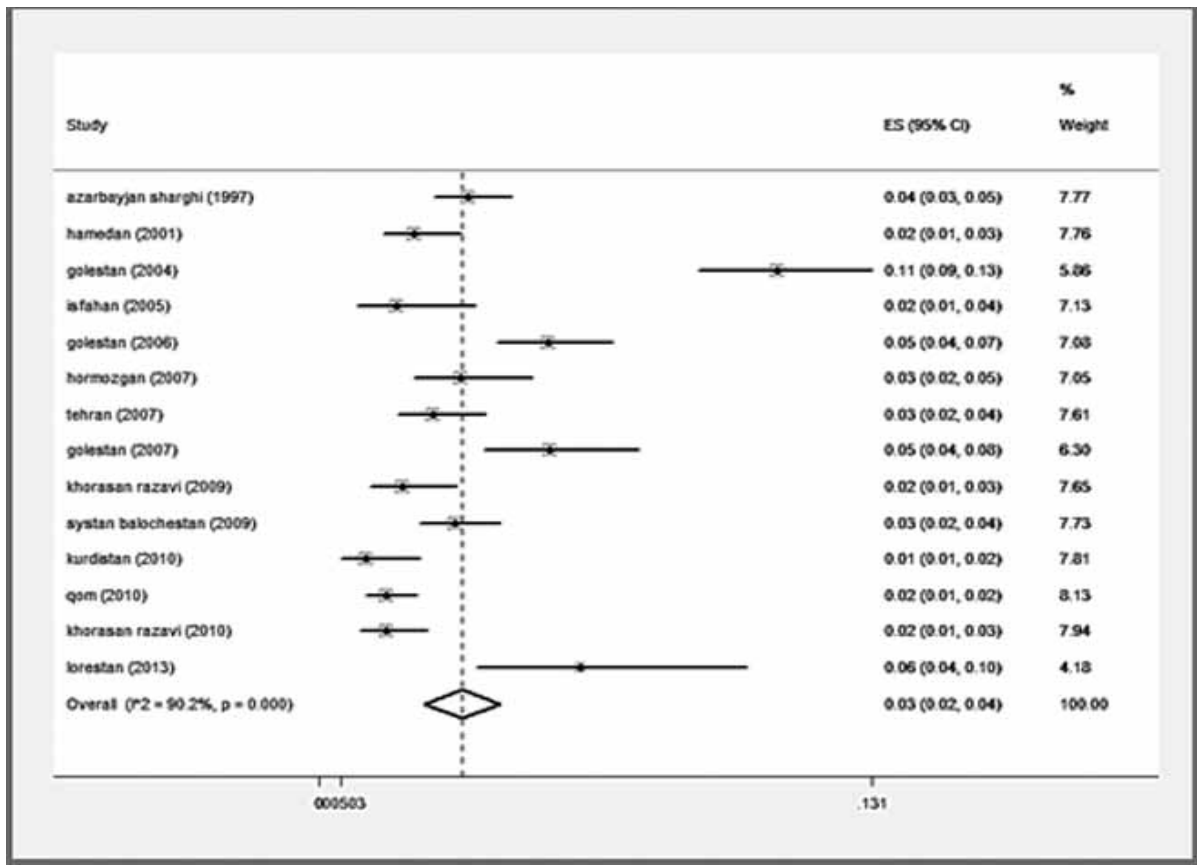

Fig. 4: Forest plot of the studies on HBV prevalence in Iran-male participants only

tan, which has a particularly high rate of $\mathrm{HBV}$, the prevalence reported in 2004 was $8.86 \%$ while it decreased to $5.1 \%$ in $2007.7,23$ Also in HBV rates were reported at $2.9 \%$ and $1.2 \%$ in 1997 and 2000 , respectively. ${ }^{21-22}$
The highest rate of $\mathrm{HBV}$ was seen in Golestan province. As described by Merat and colleagues Golestan is inhabited by the Turkaman ethnicity, which has limited contact with the rest of the country and rarely marries outside that ethnicity. 

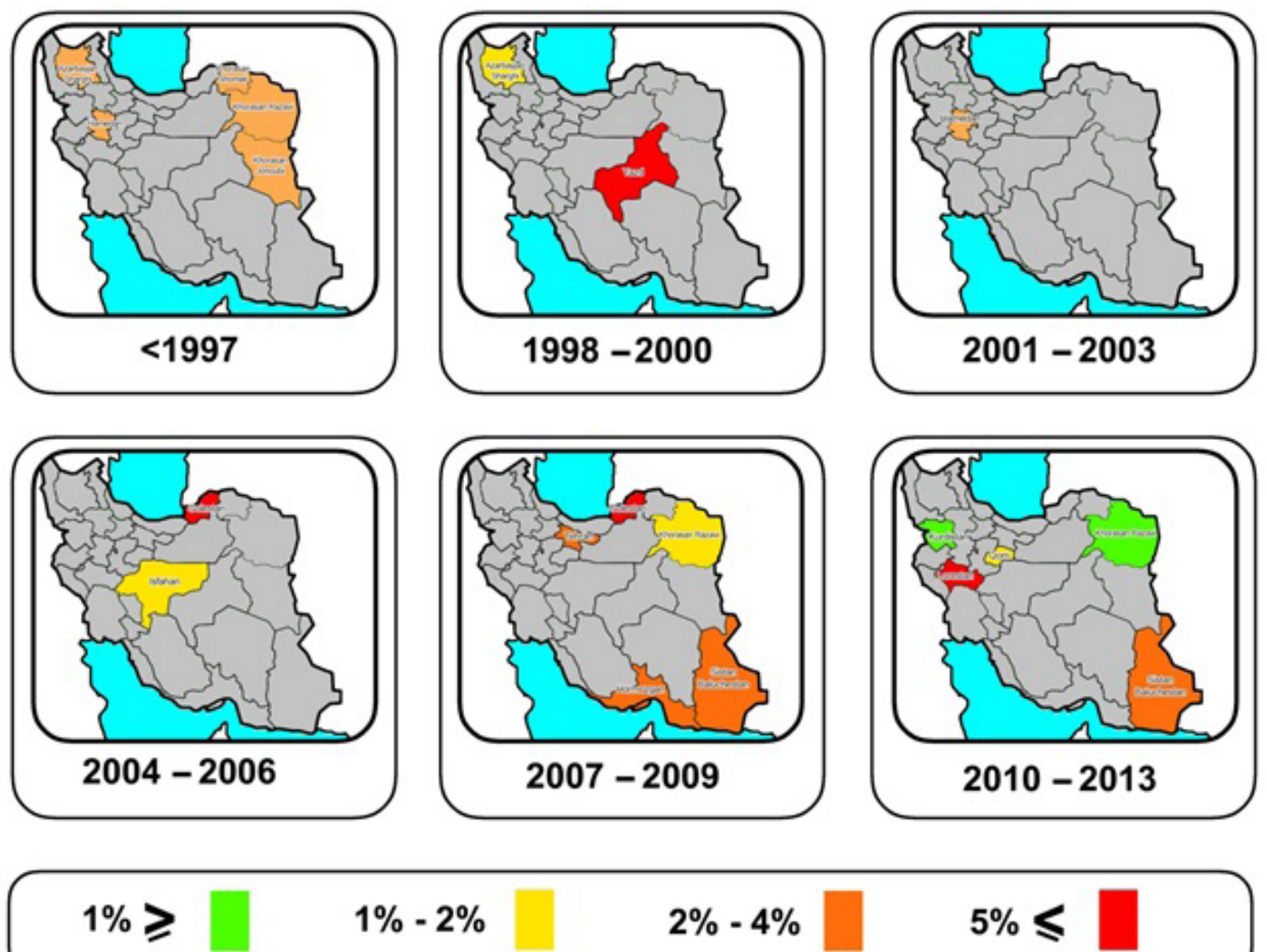

$2 \%-4 \%$

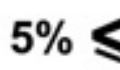

Fig. 5: The location of the studies conducted in each time category

This higher rate may partly be due to the location of Golestan, which is one of Iran's provinces with international borders and increased international communication and exposure. Recent data on HBV prevalence in Turkmenistan, Golestan's neighboring country, was not found to support this notion.

In all studies presented in this meta-analysis, HBV was more prevalent in men than women. This may be because of the fact that high risk behaviors are generally more common in men, and also because in some areas of the country, men may practice polygamy, which increases their exposure. ${ }^{7}$

The previous systematic review performed in Iran encompassed more studies in comparison with the present review, including studies of the general population, blood donors, hospital inpatients, students, and laboratory personnel. ${ }^{11}$ Although the prevalence of blood-borne diseases in for example blood donors can be used as a proxy for the prevalence in the general population, blood donors or the other groups are not a true representative sample of the general population. ${ }^{44}$ One of the strengths of this review, however, is that it only included studies that were truly conducted in the general population based on the definition provided earlier. Yet, figure 5 shows that studies on HBV prevalence are still lacking in many parts of Iran.

Another strength of this review is that only high quality articles were included. All the studies had been published in peer-reviewed journals and had therefore been subject to critical assessment prior to inclusion in this review. Most of the excluded articles either had a low quality based on STROBE quality assessment forms and therefore did not pres- 


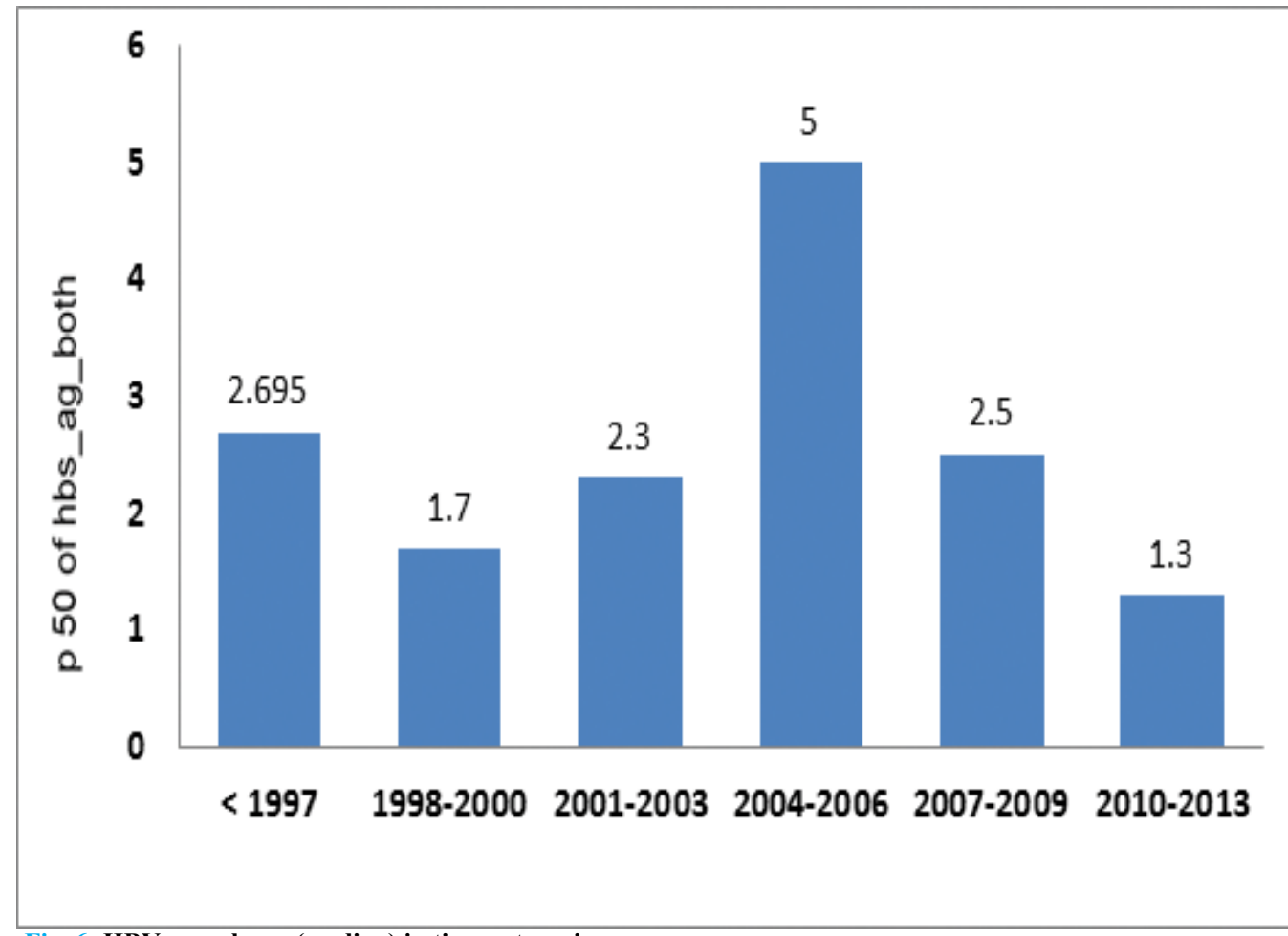

Fig. 6: HBV prevalence (median) in time categories

Study
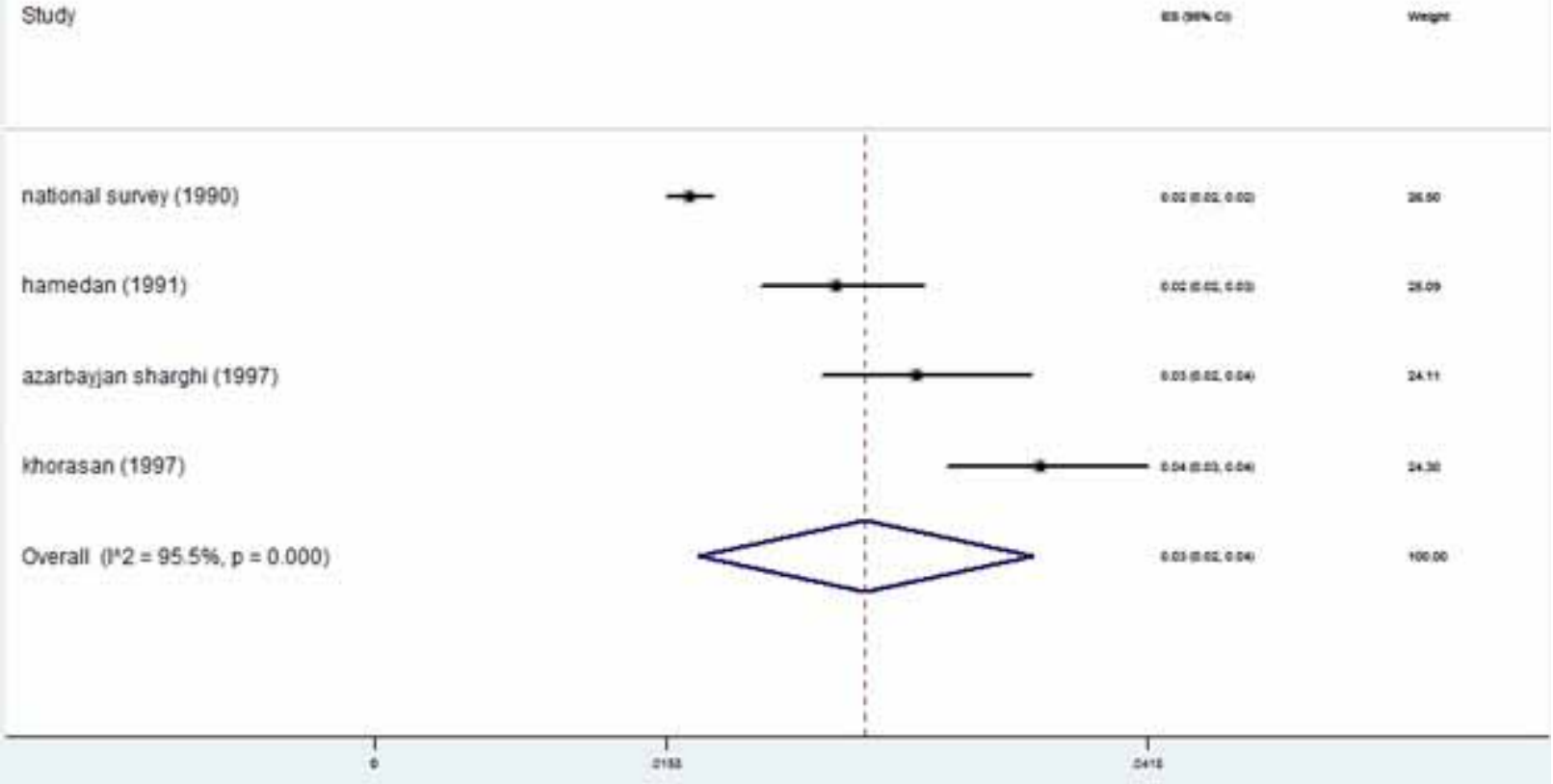

Fig. 7: Forest plot of HBV prevalence in the studies conducted prior to 1997

ent reliable data, or lacked information required for the review, such as adequate descriptive informa- tion about the population of their study, or a distinct HBV prevalence in different age groups, which can 
Study

national survey (1998)

yazd (1998)

azarbayjan sharghi (2000)

Overall $\left(\psi^{2}=93.4 \%, p=0.000\right)$

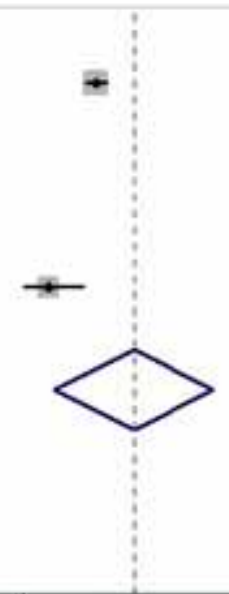

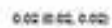

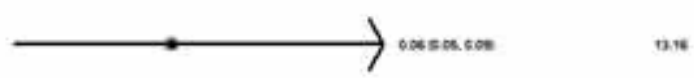

cor sen.coe

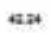

conem,eon

twe de

\section{$\operatorname{lon}$}

Fig. 8: Forest plot of $\mathrm{HBV}$ prevalence in the studies conducted during 1998-2000

Study
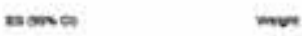

golestan (2004)

istahan (2005)

golestan (2006)

Overall $\left(0^{*} 2=98.0 \%, p=0.000\right)$
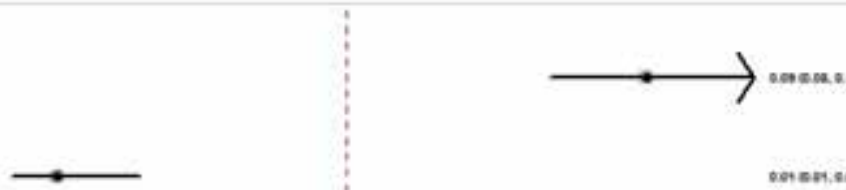

$\mathbf{m a}$

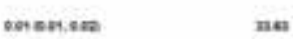

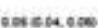

ase

oesencosen

$\infty \infty$

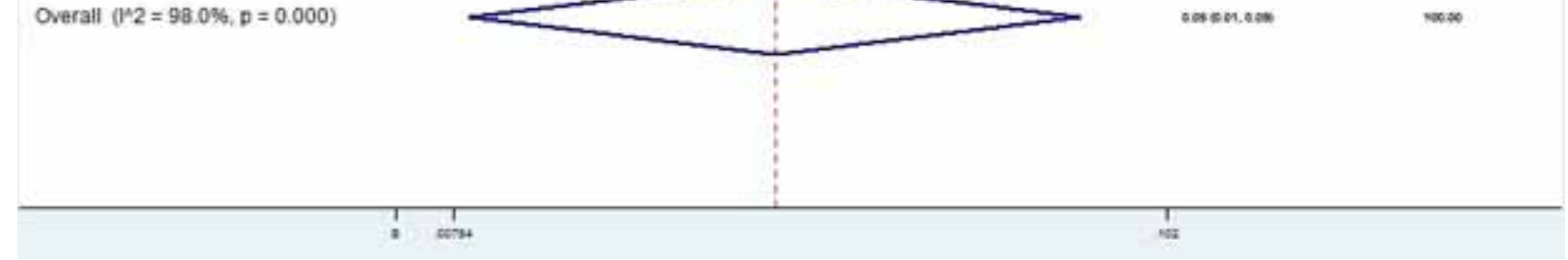

Fig. 9: Forest plot of $\mathrm{HBV}$ prevalence in the studies conducted during 2004-2006

make it difficult to use in a meta-analysis. Other studies reported prevalence based on a very small sample size, and some other studies reported overall prevalence not separated by sex.
The full-texts of many older publications in this field were not available; however in an effort to ensure the completeness of this systematic review, the related authors were contacted and the full texts 
$\operatorname{cassc}$

5

dy:

negs

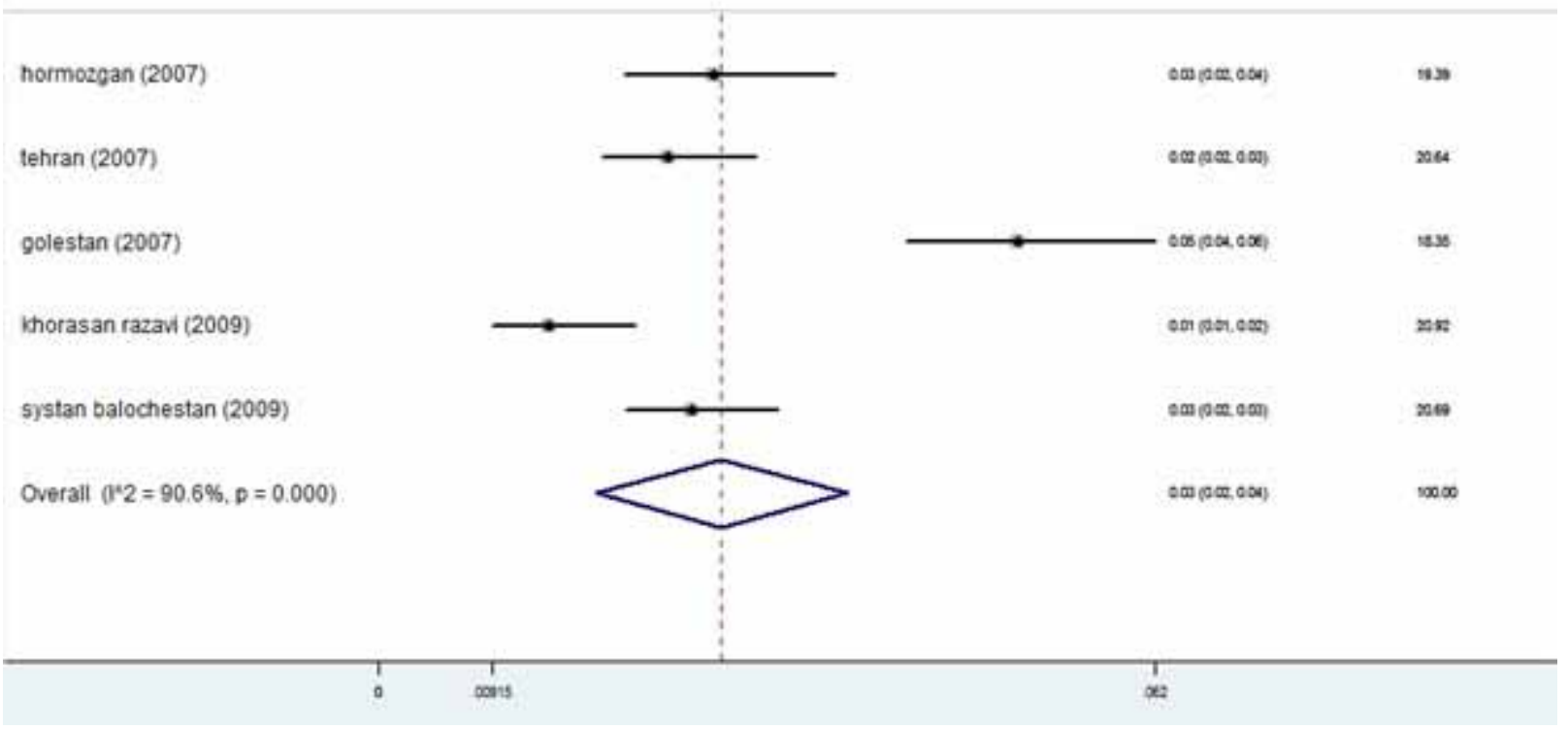

Fig. 10: Forest plot of HBV prevalence in the studies conducted during 2007-2009

Stud

canson nagr

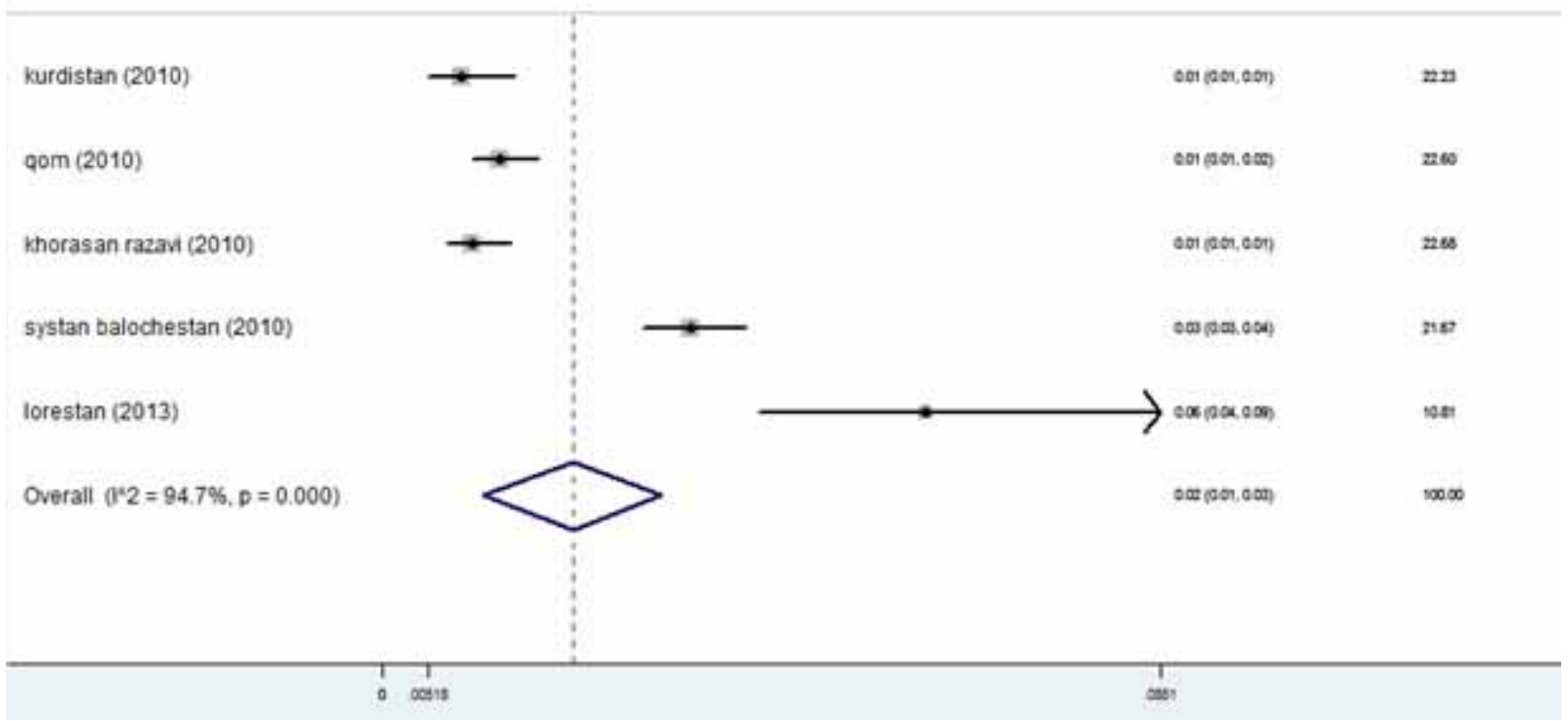

Fig. 11: Forest plot of HBV prevalence in the studies conducted during 2010-2013 


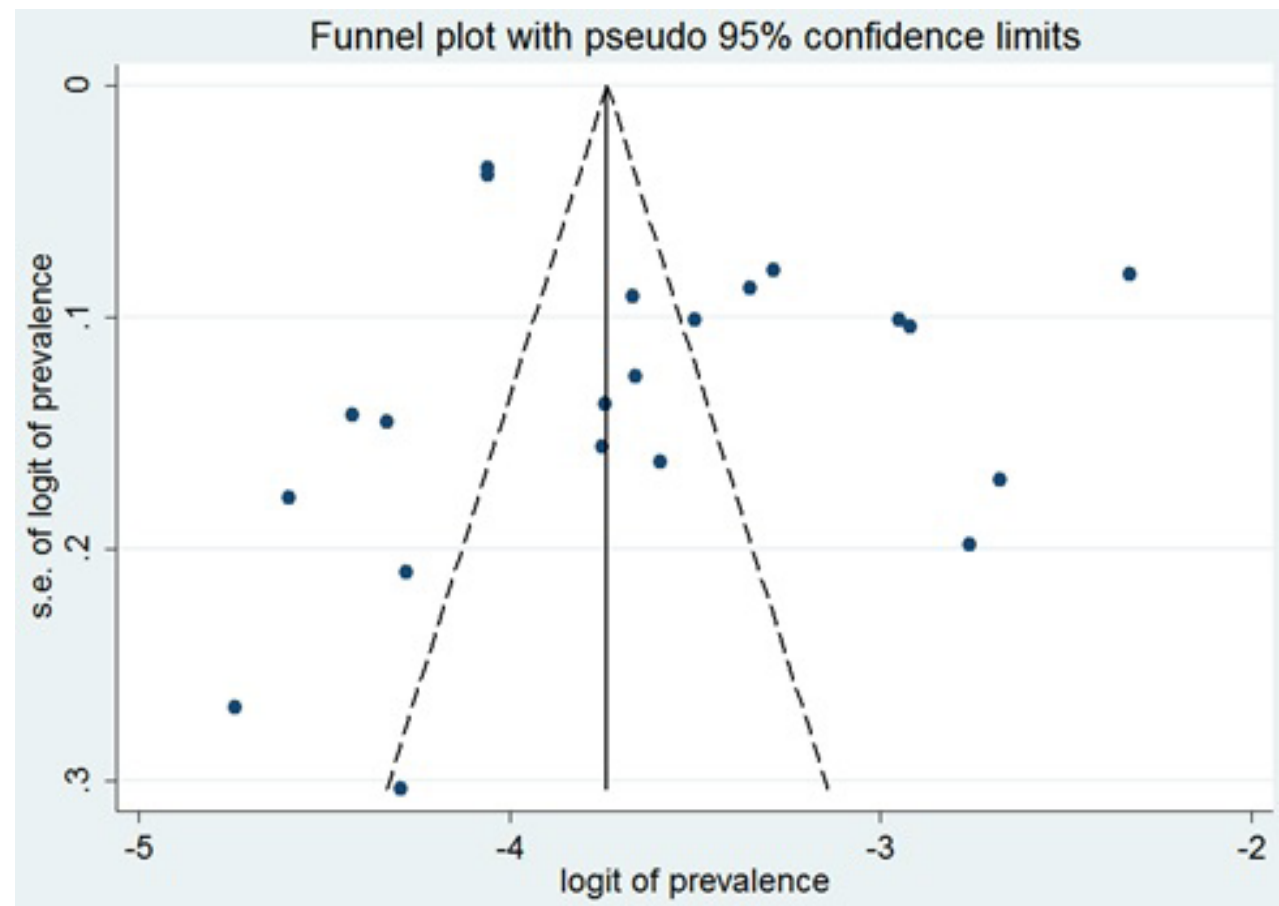

Fig. 12: Funnel plot analysis shows that there is no publication bias in this systematic review.

were obtained and included in the analyses. This is also considered one of the strengths of this review.

The most important limitation of this study on the other hand, was accessing grey literature. Although every effort was made to find as much grey literature as possible through congress websites, presentations, etc., it is still possible that some were missed.

In order to successfully cumulate data for a systematic review, certain aspects of study designs need to follow standard procedures to decrease heterogeneity. The most common sources of heterogeneity in the articles of this study were methodological and statistical. Future studies should try to use standardized formulae for sample size calculation, or standardized diagnostic kits. Also, based on the disease being studied, factors such as age, which may play an important role in the rate of prevalence, should be considered in reporting the results.

Although data from the past 25 years showed an increased trend in HBV during certain years, currently HBV prevalence is decreasing throughout Iran, especially in the younger population. This finding shows the success of the neonatal vaccination programs as well as increased general awareness of the public and healthcare providers regarding the transmission of the disease. It is recommended that future studies pay greater attention to study designs in order to increase the quality of their studies.

\section{CONFLICT OF INTEREST}

The authors declare no conflict of interest related to this work.

\section{REFERENCES}

1. Kim WR, Epidemiology of hepatitis B in the United States. Hepatology 2009;49(5 Suppl):S28-34. DOI:10.1002/hep.22975.

2. ul Haq N, Hassali MA, Shafie AA, Saleem F, Farooqui M, Aljadhey H. A cross sectional assessment of knowledge, attitude and practice towards Hepatitis B among healthy population of Quetta, Pakistan. BMC Public Health 2012,12:692. DOI:10.1186/1471-2458-12-692.

3. World Health Organization: Hepatitis B. Fact sheet no: 204. http://www.who.int/mediacentre/factsheets/fs204/en.

4. Mahoney FJ, Kane M. Hepatitis B vaccine. In: Plotkin SA Orenstein WA, eds. Vaccines, 3rd ed. Philadelphia, W.B. Saunders Company 1999:158-182.

5. Viral Hepatitis Prevention Board. Universal HB immunization by 1997: where are we now?, 1998 (Fact Sheet VHPB/ 1998/2, http://hgins.uia.ac.be/esoc/VHPB/vhfs2.html). 
6. Zali MR, Mohammad K, Farhadi A, Masjedi MR, Zargar A, Nowroozi A. Epidemiology of hepatitis B in the Islamic Republic of Iran. East Mediterr Health J 1996;2:290-8.

7. Merat S, Rezvan H, Nouraie M, Jamali A, Assari S, Abolghasemi $\mathrm{H}$, et al. The prevalence of hepatitis B surface antigen and anti-Hepatitis B Core Antibody in Iran: A PopulationBased Study. Arch Iran Med 2009;12:225-31.

8. Gholamreza R, Shahryar S, Abbasali K, Hamidreza J, Abdolvahab M, Khodaberdi K, et al. Seroprevalence of hepatitis $\mathrm{B}$ virus and its co-infection with hepatitis $\mathrm{D}$ virus and hepatitis $\mathrm{C}$ virus in Iranian adult population. Indian $\mathrm{J} \mathrm{Med}$ Sci 2007;61:263-8. DOI:10.4103/0019-5359.32092.

9. Zali MR, Mohammad K, Noorbala AA, Noorimayer B, Shahraz S. Rate of hepatitis B seropositivity following mass vaccination in the Islamic Republic of Iran. East Mediterr Health J 2005;11:62-7.

10. Alavian SM, Fallahian F, Lankarani KB. The changing epidemiology of viral hepatitis B in Iran. $J$ Gastrointestin Liver Dis 2007;16:403-6.

11. Alavian SM, Hajarizadeh B, Ahmadzade-Asl Ma, Kabir A, Bagheri-Lankarani K. Hepatitis B virus infection in Iran: a Systematic Review. Hepat Mon 2008;8:281-94.

12. Shapiro, Haroutune K. Armenian ; Sam (1998). Epidemiology and health services. New York [u.a.]: Oxford Univ. Press.

13. Lavanchy D. Hepatitis B virus epidemiology, disease burden, treatment and current and emerging prevention and control measures. J Viral Hepat 2004;11:97-107. DOI:10.1046/ j.1365-2893.2003.00487.x.

14. Mast EE, Margolis HS, Fiore AE, Brink EW, Goldstein ST, Wang SA, et al. A comprehensive immunization strategy to eliminate transmission of hepatitis B virus infection in the United States: recommendations of the Advisory Committee on Immunization Practices (ACIP) part 1: immunization of infants, children, and adolescents. MMWR Recomm Rep 2005;54:1-31.

15. Mast EE, Weinbaum CM, Fiore AE, Alter MJ, Bell BP, Finelli L, et al. A comprehensive immunization strategy to eliminate transmission of hepatitis B virus infection in the United States-recommendations of the Advisory Committee on Immunization Practices (ACIP) Part II: Immunization of adults. MMWR Recomm Rep 2006;55:1-33.

16. McMahon BJ. Epidemiology and natural history of hepatitis B. Semin Liver Dis 2005;25(Suppl 1):3-8. DOI:10.1055/s-2005-915644.

17. Mast EE, Alter MJ, Margolis HS. Strategies to prevent and control hepatitis $\mathrm{B}$ and $\mathrm{C}$ virus infections: a global perspective. Vaccine 1999;17:1730-3. DOI:10.1016/S0264-410X (98)00415-0.

18. Begg CB, Mazumdar M. Operating characteristics of a rank correlation test for publication bias. Biometrics 1994;50:1088-101. DOI:10.2307/2533446.

19. Egger M, Davey Smith G, Schneider M, Minder C. Bias in metaanalysis detected by a simple, graphical test. BMJ 1997;315:62934. DOI:http://dx.doi.org/10.1136/bmj.315.7109.629.
20. Calvo-Muñoz I, Gómez-Conesa A, Sánchez-Meca J. Prevalence of low back pain in children and adolescents: a meta-analysis. BMC Pediatr 2013;13:14. DOI:10.1186/1471-2431-13-14.

21. Bayat-Makou J, Shahnazi A, Koushavar H. [Prevalent infections in north-west region of Tabriz]. Med J Tabriz Univ Med Sci 2003;59(30).

22. Hasanzadeh A, Mohammad K. [The prevalence and related risk factors of HBsAg positivity: East Azarbaijan1996]. $J$ Res Med Sci 2001;3:126-7.

23. Abdolahi N, Keshtkar AA, Semnani S, Roshandel GR, Beshrat S, Joshaghani HR. [HBV Seroprevalence among Golestan Adults]. Iran J Epidemiol 2006;4:35-40.

24. Jamali R, Khonsari M, Merat S, Khoshnia M, Jafari E, Bahram Kalhori A, et al. Persistent alanine aminotransferase elevation among the general Iranian population: Prevalence and causes. World J Gastroenterol 2008;14:286771. DOI:http://dx.doi.org/10.3748/wjg.14.2867.

25. Amini S, Mahmoodi MF, Andalibi S, Solati AA. Seroepidemiology of hepatitis B, delta and human immunodeficiency virus infections in Hamadan province,Iran: a population based study. J Trop Med Hyg 1993;96:277-87.

26. Alizadeh AH, Ranjbar M, Ansari S, MirArab A, Alavian SM, Mohammad K, et al. Seroprevalence of hepatitis B in Nahavand, Islamic Republic of Iran. East Mediterr Health J 2006;12:528-37.

27. Nokhoudian Z, Kasaeian N, Ataei B, Javadi AA, Shoaei P, Farajzadegan Z, et al. Hepatitis B markers in isfahan, central iran: a population-based study. Hepat Mon 2009:12-6.

28. Farhat A, Khademi G, Mazlouman SJ. The prevalence of hepatitis B carrier state in Khorassan province of Iran. Saudi Med J 2003;24:549-51.

29. Shakeri MT, Foghanian B, Nomani H, Ghayour-Mobarhan M, Nabavinia MS, Rostami S, et al. The prevalence of hepatitis B Virus Infection in Mashhad, Iran: A PopulationBased Study. Iran Red Cres J 2013;15:245-8. DOI:10.5812/ ircmj.8200.

30. Fathimoghaddam F, Hedayati-Moghaddam MR, Bidkhori HR, Ahmadi S, Sima HR. The prevalence of hepatitis B antigen-positivity in the general population of Mashhad, Iran. Hepat Mon 2011;11:346-50.

31. Alavian SM, Tabatabaei SV, Ghadimi T, Beedrapour F, KafiAbad SA, Gharehbaghian A, et al. Seroprevalence of hepatitis $B$ virus infection and Its Risk Factors in the West of Iran: A Population-based Study. Int J Prev Med 2012;3:770-5.

32. Papi OA, Saki M, Mokhayeri H, Sheikh Azadi A, Chegeni Sharafi A, Nabavi M, et al. Seroepidemiologic study of hepatitis B in Kouhdasht and Sepid dasht districts. J Lorestan Univ Med Sci 2012;15:38-43.

33. Ghadir MR, Belbasi M, Heidari A, Jandagh M, Ahmadi I, Habibinejad H, et al. Distribution and risk factors of Hepatitis B Virus Infection in the General Population of Central Iran. Hepat Mon 2012;12:112-7. DOI:10.5812/ hepatmon. 822 . 
34. Ansari-Moghaddam A, Ostovaneh MR, Sharifi Mood B, Sanei-Moghaddam E, Modabbernia A, Poustchi H. Seroprevalence of hepatitis B surface Antigen and Anti Hepatitis C Antibody in Zahedan City, Iran: A PopulationBased Study. Hepat Mon 2012;12:e6618. DOI:10.5812/ hepatmon.6618.

35. Salehi M, Sanei Moghadam E. Prevalence of HBV infection in Zahedan. Tabibe Shargh 2003;5:245-50.

36. Salehi M, Alavian SM, Tabatabaei SV, Izadi Sh, Sanei Moghaddam E, Amini Kafiabad S, et al. Seroepidemiology of HBV Infection in South-East of Iran; A Population Based Study. Iran Red Crescent Med J 2012;14:283-8.

37. Sharifi MR, Ghoraishian SM. [Epidemiology of chronic vector for Hepatitis B surface antigen in Yazd]. J Shahid Sadoughi Univ Med Sci 1999;2:5-9.

38. Ay P, Torunoglu MA, Com S, Çipil Z, Mollahaliloğlu S, Erkoç Y, et al. Trends of hepatitis B notification rates in Turkey, 1990 to 2012. Euro Surveill 2013; pii: 20636. DOI:http://dx.doi. org/10.2807/1560-7917.ES2013.18.47.20636.

39. Memish ZA, Knawy BA, El-Saed A. Incidence trends of viral hepatitis A, B, and C. Int J Infect Dis 2010;14:e115-20. DOI:10.1016/j.ijid.2009.03.027.

40. Faleh FZ, Ayoola EA, Al-Jeffry M, Arif M, Al-Rashed RS, Ramia S. Integration of hepatitis B vaccine into the expanded program on immunization: The Saudi Arabian experience. Ann Saudi Med 1993;13:231-6.

41. William I. New epidemiology data of hepatitis B and C. Am J Manag Care (AMJC) 1998;4:S667-70.

42. Jones L, Atkinson A, Porcellato L, Bates G, McCoy E, Beynon C, McVeigh J, Bellis M. A systematic review of qualitative research on the views, perspectives and experiences of hepatitis $\mathrm{B}$ and $\mathrm{C}$ testing among practitioners and people at greatest risk of infection. Centre for Public Health, Research Directorate, Faculty of Health and Applied Social Sciences, Liverpool John Moores University. Final report.

43. Tasyaran MA. Epidemiology of the HBV. In: Tekeli E, Balı I'dt, editors. Viral hepatitis 2003 [In Turkish]. 1st ed. Ankara: Viral Hepatitle Savasım Dernegi 2003.p.121-8.

44. European Centre for Disease Prevention and Control. Hepatitis B and C in the EU neighbourhood: prevalence, burden of disease and screening policies. Stockholm: ECDC; 2010. 